\title{
Crescimento e desenvolvimento de mudas de tomateiro e melão empre- gando os métodos de irrigação por microaspersão, inundação subsuperficial e flutuação.
}

\author{
Jerônimo L. Andriolo; Moisés P. Boemo; Jorge V. Bonini \\ UFSM - CCR - Depto. de Fitotecnia, 97.105 - 900, Santa Maria - RS; Email: andriolo@creta.ccr.ufsm.br.
}

\section{RESUMO}

Dois experimentos foram realizados na Universidade Federal de Santa Maria, RS, no verão do ano 2000, para comparar o crescimento e desenvolvimento de mudas de tomateiro e melão nos métodos de irrigação por microaspersão, inundação subsuperficial e flutuação. A semeadura foi efetuada em bandejas de poliestireno com 128 células, empregando como substrato um volume de $20 \mathrm{~mL}$ de turfa em cada célula, o qual armazenou um volume de água retido de $9 \mathrm{~mL}$. Nos métodos da inundação subsuperficial e da flutuação foram construídos reservatórios com $0,80 \mathrm{~m}$ de largura, $1,70 \mathrm{~m}$ de comprimento e $0,10 \mathrm{~m}$ de profundidade. No método da inundação subsuperficial, o volume de água contido no reservatório foi drenado após cada irrigação, enquanto naquele da flutuação as bandejas permaneceram flutuando sobre a superfície da água durante todo o período experimental. Em cada experimento, os três métodos foram comparados como tratamentos, empregando-se três conjuntos de duas bandejas para cada tratamento, dispostas lado a lado. O dispositivo experimental foi duplicado para testar os mesmos tratamentos nas espécies do tomateiro e do melão. Periodicamente foi feita coleta de plantas para determinação da massa seca da parte aérea e radicular, da altura das plântulas e contagem do número de folhas. Os resultados indicaram que a inundação subsuperficial foi o método que mais favoreceu o desenvolvimento e o crescimento da parte aérea das mudas, tanto para o tomateiro como para o melão.

\begin{abstract}
Growth and development of tomato and melon seedlings using irrigation methods of overhead, ebb-and-flow and floating.

Two experiments were carried out at the Universidade Federal de Santa Maria (Brazil), in summer 2000 to compare the growth and development of tomato and cucumber seedlings using irrigation methods of overhead, ebb-and-flow and floating. Sowing was done in polyestyrene trays with 128 cells, filled with $20 \mathrm{~mL}$ of peat and containing $9 \mathrm{~mL}$ of water in each cell. For the ebb-and-flow and floating methods, reservoirs with $0.80 \mathrm{~m}$ width, $1.70 \mathrm{~m}$ length and $0.10 \mathrm{~m}$ depth were constructed on the soil surface. In the ebb-andflow method, water was drained out of the reservoir just after each irrigation, while in the floating method trays floated on the water surface till the end of experiments. In each experiment, the three methods were compared as treatments, using three sets of two trays for each treatment, placed side by side. Two identical experimental set-ups were used to test concomitantly the same treatments on tomato and melon seedlings. Periodically destructive measurements were made to determine shoot and root dry matter, plant height and number of leaves. Shoot growth and development of tomato and melon seedlings were higher in the ebb-and-flow method.
\end{abstract}

Keywords: Lycopersicon esculentum, Cucumis melo, dry matter, number of leaves.
Palavras-chave: Lycopersicon esculentum, Cucumis melo, massa seca, número de folhas.

(Aceito para publicação em 28 de setembro de 2.001)

\begin{abstract}
$\mathrm{A}^{\mathrm{r}}$ regularidade de oferta de hortaliças ao longo do ano é um dos principais desafios atuais da olericultura. Para tanto, sistemas de produção com tecnologia mais sofisticada estão sendo cada vez mais empregados, como os cultivos em ambientes protegidos, hidropônicos e em substrato. Face à complexidade crescente desses sistemas de produção, a etapa referente à produção de mudas tende a ser feita por produtores especializados, que atuam como fornecedores de mudas para aqueles dedicados à produção final. Esse segmento da olericultura está fortemente desenvolvido em outros países (Nicola \& Basocu, 2000). No Brasil, horticultores especializados nessa atividade estão surgindo em vários Estados.
\end{abstract}

Os principais fatores do ambiente que afetam a germinação e crescimento das mudas de hortaliças são a temperatura e a umidade. $\mathrm{O}$ tomateiro tem a germinação otimizada com temperaturas de $25^{\circ} \mathrm{C}$ (CTIFL, 1995), enquanto que para o melão esta temperatura se situa entre 25 e $30^{\circ} \mathrm{C}$ (Delacecca, 1985). A manutenção de teores elevados de umidade tanto do ar como do substrato é essencial para o crescimento das plântulas, constituindo-se no principal elemento de manejo da produção de mudas. No período estival, quando a radiação solar, a temperatura e o déficit de saturação do ar são elevados, o método de irrigação empregado para fornecer água às mudas influencia tanto a disponibilidade hídrica em torno das raízes, como a umidade do ar em torno da parte aérea das plântulas. O método empregado pode repercutir também no custo de produção das mudas, devido aos equipamentos, automatismos e/ou mão-de-obra exigidos.

O objetivo deste trabalho foi comparar o crescimento e desenvolvimento de mudas de tomateiro e melão em condição estival, empregando os métodos de irrigação por microaspersão, inundação subsuperficial e flutuação.

\section{MATERIAL E MÉTODOS}

Dois experimentos foram conduzidos no Departamento de Fitotecnia da Universidade Federal de Santa Maria, 
RS, de 3 a 28 de janeiro (experimento 1) e 7 a 31 de janeiro de 2000 (experimento 2), no interior de um túnel semicircular de polietileno (5 $\mathrm{m}$ de largura e $20 \mathrm{~m}$ de comprimento), localizado a aproximadamente $50 \mathrm{~m}$ da estação climatológica do mesmo departamento. Nesta estação, foram medidas diariamente a temperatura e a umidade relativa do ar durante o período de realização dos experimentos. A semeadura do tomateiro, híbrido Monte Carlo, e do melão, híbrido Hales Best Jumbo, foi efetuada em bandejas de poliestireno com 128 células, empregando turfa como substrato. $\mathrm{O}$ volume médio de substrato contido em cada célula foi de $20 \mathrm{~mL}$ e o volume de água retido de $9 \mathrm{~mL}$. Imediatamente após a semeadura, as bandejas foram transferidas para os dispositivos experimentais relativos a cada um dos três métodos testados, instalados linearmente no eixo central interno do túnel de polietileno.

No método de irrigação por microaspersão, as bandejas foram dispostas sobre estrados metálicos, com altura de 1,20 $\mathrm{m}$ acima do nível do solo. Os microaspersores foram instalados a 1,10 $\mathrm{m}$ acima da superfície das bandejas, espaçados de 1,50 m entre si, com sobreposição da superfície irrigada de $20 \%$. No método de irrigação por inundação subsuperficial, foi construído sobre a superfície do solo um reservatório com 0,80 m de largura, 1,70 m de comprimento e $0,10 \mathrm{~m}$ de profundidade, com declividade de $0,5 \%$. Um tubo de PVC de diâmetro igual a $25 \mathrm{~mm}$ foi instalado no fundo do reservatório, a fim de permitir seu esvaziamento completo após cada irrigação. O período de tempo transcorrido desde o acionamento da bomba até o enchimento completo do reservatório foi de 7 minutos e o volume de água fornecido de 129,2 L. Após o enchimento, a bomba permaneceu em funcionamento durante um período adicional de 8 minutos, sendo o fluxo de água drenado simultaneamente por transbordamento do reservatório e pelo tubo de drenagem situado na parte inferior do mesmo. Esse período foi destinado a assegurar a completa saturação hídrica do substrato por capilaridade. Ao final do mesmo, a bomba foi desligada por intermédio de um temporizador e o tempo transcorrido para o esvaziamen- to completo do reservatório pelo tubo de drenagem foi de 5 minutos. Dessa forma, em cada irrigação a lâmina d'água permaneceu em contato com a superfície inferior das bandejas por um período não inferior a 8 minutos. Dois suportes lineares constituídos por um tubo de polietileno com diâmetro de 50 $\mathrm{mm}$ foram colocados entre o fundo do reservatório e a parte inferior das bandejas, para evitar o contato das raízes com o volume residual de água contido no fundo do mesmo após o seu esvaziamento.

No método de irrigação por flutuação foi construído um reservatório idêntico àquele do método anterior, instalado porém sem nenhuma declividade. Eliminaram-se também os tubos de PVC destinados à drenagem $\mathrm{e}$ suporte das bandejas, permanecendo as mesmas a flutuar sobre a superfície da água contida no interior do reservatório durante todo o período experimental.

Durante a realização dos experimentos, o filme de polietileno da cobertura do túnel permaneceu soerguido em aproximadamente $1,20 \mathrm{~m}$ em cada uma das extremidades laterais, de forma a assegurar a ventilação no seu interior e ao mesmo tempo proteger as mudas de eventuais precipitações pluviométricas. Nos métodos da microaspersão e da inundação subsuperficial, a irrigação foi efetuada diariamente de forma a manter o teor de umidade do substrato sempre próximo da capacidade máxima de retenção de água. Para isso, estimou-se a evapotranspiração (ETP) diária na superfície das bandejas pelo método do Tanque Classe A, para o qual o valor do coeficiente de tanque (Kp) foi determinado pela seguinte relação (Snyder, 1992, citado por Pereira et al., 1997):

$\mathrm{Kp}=0,482+0,024 \mathrm{Ln}(\mathrm{F})-$ $0,000376 \mathrm{U}+0,0045 \mathrm{UR}$,

para um valor de $\mathrm{F}=10 \mathrm{~m}$, sendo $U$ a velocidade do vento medida a $10 \mathrm{~m}$ de altura, em km.dia ${ }^{-1}$, e $U R$ a umidade relativa diária média do ar, em $\%$.

A freqüência das irrigações foi determinada de forma a repor os volumes perdidos pela ETP, antes de atingir o limite de $50 \%$ do volume retido no interior do substrato de cada célula, considerado como a fração da água facilmente utilizável (Gras, 1987; Andriolo, 1999).
No método da flutuação, o volume de água perdido pela evapotranspiração foi reposto diariamente no reservatório.

Em cada experimento, os três métodos foram comparados como tratamentos, empregando-se três conjuntos de duas bandejas para cada tratamento, dispostas lado a lado. O dispositivo experimental foi duplicado para testar concomitantemente os mesmos tratamentos nas espécies do tomateiro e do melão. Foram empregadas no total 18 bandejas para cada espécie.

O desenvolvimento das mudas foi determinado por contagem do número de folhas em intervalos semanais, desde a emergência até o final do período experimental. $\mathrm{O}$ crescimento foi medido através da acumulação da massa seca no decorrer do período experimental, em 3 grupos de 5 plântulas, coletadas ao acaso nas duas bandejas, para cada tratamento. Após a coleta, as mudas foram retiradas das bandejas e as raízes lavadas em água corrente até a eliminação total das partículas do substrato. A parte aérea foi separada do sistema radicular mediante um corte na região do coleto da muda e submetida a secagem em estufa, a temperatura de $60^{\circ} \mathrm{C}$, durante uma semana, sendo a seguir pesada para determinação da quantidade de massa seca acumulada. Para cada tratamento foram estimadas a média e a variância, sendo as médias comparadas pelo teste $t$ de Student, em nível de 5\% de probabilidade de erro.

\section{RESULTADOS E DISCUSSÃO}

Os valores médios diários de temperatura flutuaram entre 21,7 e $30,5^{\circ} \mathrm{C}$ e da umidade do ar entre 51 e $97 \%$ (Figura 1). Para o tomateiro, no experimento 1 foi observada uma tendência de crescimento mais elevado da parte aérea no método da inundação subsuperficial, diferindo significativamente dos outros dois métodos (Figura 2a e Tabela 1). No método da flutuação houve tendência a um maior crescimento em relação ao método da microaspersão. O crescimento das raízes mostrou tendências similares nos três métodos (Figura 2b). No experimento 2, o método da inundação subsuperficial apresentou tendência de crescimento da 
Tabela 1. Número de folhas (NF), altura (Alt, cm) e massa seca (g) da parte aérea (MSa) e das raízes (MSr) das mudas de tomateiro e melão produzidas empregando os métodos de irrigação por microaspersão, inundação subsuperficial e flutuação, nos experimentos 1 e 2 . Santa Maria, UFSM, 2000.

\begin{tabular}{|c|c|c|c|c|c|c|c|c|c|c|}
\hline \multirow{2}{*}{ Exp } & \multirow{2}{*}{ Tratamentos } & \multicolumn{4}{|c|}{ Tomateiro } & \multicolumn{5}{|c|}{ Melão } \\
\hline & & NF & Alt & MSa & $\mathrm{MSr}$ & NF & $\overline{\text { Alt }}$ & & MSa & MSr \\
\hline$\overline{1}$ & Microaspersão & 3 & 4,2 & $0,027 \quad b$ & $0,018 \mathrm{a}$ & 2 & 4,5 & c & $0,056 \quad b$ & $0,057 \quad b$ \\
\hline 1 & $\begin{array}{l}\text { Inundação } \\
\text { subsuperficial }\end{array}$ & $6 a$ & $14,5 a$ & $0,153 a$ & $0,028 a$ & $6 a$ & $18,0 \mathrm{a}$ & & $0,500 a$ & $0,094 \mathrm{a}$ \\
\hline 1 & Flutuação & $4 \mathrm{~b}$ & $7,8 \quad b$ & $0,069 \quad b$ & $0,023 a$ & $4 \mathrm{~b}$ & 13,0 & $b$ & $0,431 a$ & $0,058 \quad b$ \\
\hline 2 & Microaspersão & $2 b$ & $3,6 \quad c$ & $0,039 \quad b$ & $0,032 \quad b$ & $3 \mathrm{~b}$ & 6,0 & c & 0,128 & $0,072 \mathrm{a}$ \\
\hline 2 & $\begin{array}{l}\text { Inundação } \\
\text { subsuperficial }\end{array}$ & $7 a$ & $17,0 \mathrm{a}$ & $0,233 a$ & 0,069 a & $7 a$ & $21,0 \mathrm{a}$ & & $0,615 a$ & $0,115 \quad b$ \\
\hline 2 & Flutuação & $2 b$ & $5,5 \quad b$ & $0,037 \quad b$ & $0,036 \quad b$ & $3 b$ & $11,0 \mathrm{~b}$ & & $0,231 \quad b$ & $0,140 \quad b$ \\
\hline
\end{tabular}

*/ Médias seguidas pela mesma letra na posição vertical não diferem significativamente a 5\% de probabilidade pelo teste $\underline{\mathbf{t}}$.

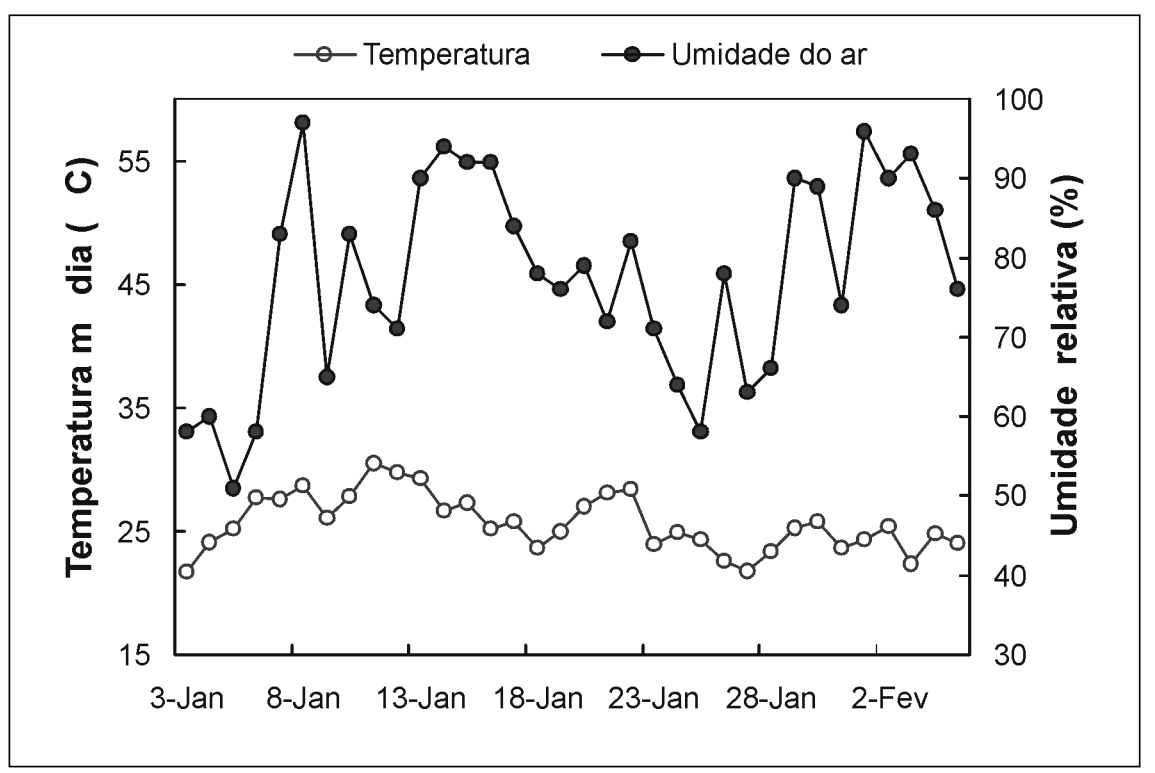

Figura 1. Valores de temperatura média e umidade do ar medidos na Estação Climatológica do Departamento de Fitotecnia no período de realização dos experimentos 1 e 2. Santa Maria, UFSM, 2000.

parte aérea superior aos demais já no início do período experimental e os valores de massa seca medidos nos métodos da flutuação e da microaspersão foram similares (Figura 2c e Tabela 1). Quanto às raízes, crescimento mais elevado foi observado nas três últimas coletas nas mudas irrigadas pelo método da inundação subsuperficial, diferindo significativamente dos outros dois ao final do período experimental (Figura 2d e Tabela 1).

No melão, o método da inundação subsuperficial induziu um maior crescimento da parte aérea nos dois experimentos, com tendência visível à partir da segunda determinação efetuada (Figura 3 a,c). No experimento 1, foi ob- servada tendência semelhante, porém com valores inferiores no método da flutuação, o qual não diferiu significativamente da inundação subsuperficial ao final do experimento (Figura $3 \mathrm{a}$ e Tabela 1). Nos dois experimentos, o método da microaspersão induziu um crescimento reduzido da parte aérea das mudas. Quanto às raízes, os métodos da inundação subsuperficial no experimento 1 (Figura 3b) e da flutuação no experimento 2 (Figura 3d) mostraram tendência a favorecer o crescimento deste compartimento, quando comparados com a microaspersão.

Os resultados mostrados neste trabalho indicaram que a inundação subsuperficial foi o método que mais favoreceu o crescimento da parte aérea das mudas, nas duas espécies testadas, confirmando as observações de Nicola $\&$ Basocu (2000). Isso pode ser atribuído ao fato de este método fornecer água às mudas sem interferir negativamente sobre outros processos que condicionam o crescimento, como a disponibilidade de oxigênio e nutrientes. $\mathrm{O}$ contato permanente das raízes com a água no método da flutuação diminui a disponibilidade de oxigênio no meio radicular, interferindo negativamente sobre aqueles processos. O controle do teor de umidade em torno das raízes é uma das etapas fundamentais do manejo das plantas em cultivo fora do solo (Marfa \& Guri, 1999). Por outro lado, o método da microaspersão fornecendo água com elevada freqüência ao longo do dia, favorece a lixiviação dos nutrientes contidos no substrato. Esse fenômeno é mais intenso quando são utilizados substratos com baixa capacidade de troca de cátions, como aqueles provenientes de resíduos vegetais (Sánchez, 1999). Quando este método de irrigação for utilizado nos meses de verão, a fertirrigação periódica se mostra necessária para induzir o crescimento normal das mudas.

Os resultados do trabalho indicaram que o método da inundação subsuperficial se constitui em uma alternativa para a produção de mudas de hortaliças de alta qualidade nos períodos quentes do ano. Entretanto, dispositivos de cultura capazes de recolher e reutilizar os volumes de água drenados após cada irrigação devem ser 
construídos para utilizar racionalmente os recursos hídricos. Isto pode ser obtido facilmente mediante sistemas automatizados como aqueles atualmente empregados nos sistemas hidropônicos de cultivo (Andriolo, 1999). Precauções também devem ser adotadas nos dias anteriores ao transplante e/ou plantio das mudas no local definitivo, pois plantas cultivadas com elevada disponibilidade hídrica tendem a reduzir o teor de massa seca dos tecidos (Bakker, 1991), diminuindo a percentagem de pegamento. Um período prévio de adaptação de alguns dias com fornecimento limitado de água antes do plantio pode então ser necessário em função do sistema de cultivo para o qual as mudas vierem a ser destinadas.

\section{LITERATURA CITADA}

ANDRIOLO, J.L. Fisiologia das culturas protegidas. Santa Maria: Editora da UFSM, 1999. 142 p. BAKKER, J.C. Analysis of humidity effects on growth and production of glasshouse fruit vegetables. Wageningen: Wageningen Agricultural University, 1991, 155 p. (Dissertation).

CTIFL. Centre Technique Interprofessionel des Fruits e des Légumes. Maîtrise de la conduite climatique. Paris: ctIFL, 1995. 127 p.

DELACECCA, V. Regolazione della temperatura. In: Serre e tunel. Collana, Itália: REDA, 1985. p. 88-101.

GRAS, R. Proprietés physiques des substrats. In: BLANC, D. ed. Les cultures hors sol. Paris: INRA, 1987. p. 80-126.

MARFA, O.; GURI, S. Física de substratos y oxigenación del medio radicular. In: FERNANDÉZ, M.F.; GÓMEZ, I.M.c. ed. Cultivos sin suelo II. Almeria: DGIFA/FIAPA/Caja Rural de Almeria. 1999. p. 93 - 106.

NICOLA, S.; BASOCU, L. Overhead, ebb and flow, and floatation: analysis of three irrigation systems to grow lettuce transplants. In: INTERNATIONAL SYMPHOSIUM ON PROTECTED CULTIVATION IN MILD WINTER CLIMATES: CURRENT TRENDS FOR SUSTAINABLE TECHNOLOGIES, 1., 2000, Cartagena. Abstracts... Cartagena: ISHS, 2000, p. 143.

PEREIRA, A.R.; VILLA NOVA, N.A; SEDIYAMA, G.C. Evapo(transpi)ração. Piracicaba: FEALQ, $1997.183 \mathrm{p}$.

SÁNCHEZ, F.P. Propriedades y características de los substratos. Turba y fibra de coco. In: FERNANDÉZ, M.F.; GÓMEZ, I.M.C. ed. Cultivos sin suelo II, Almeria: DGIFA/FIAPA/Caja Rural de Almeria. 1999. p. 65 - 92.

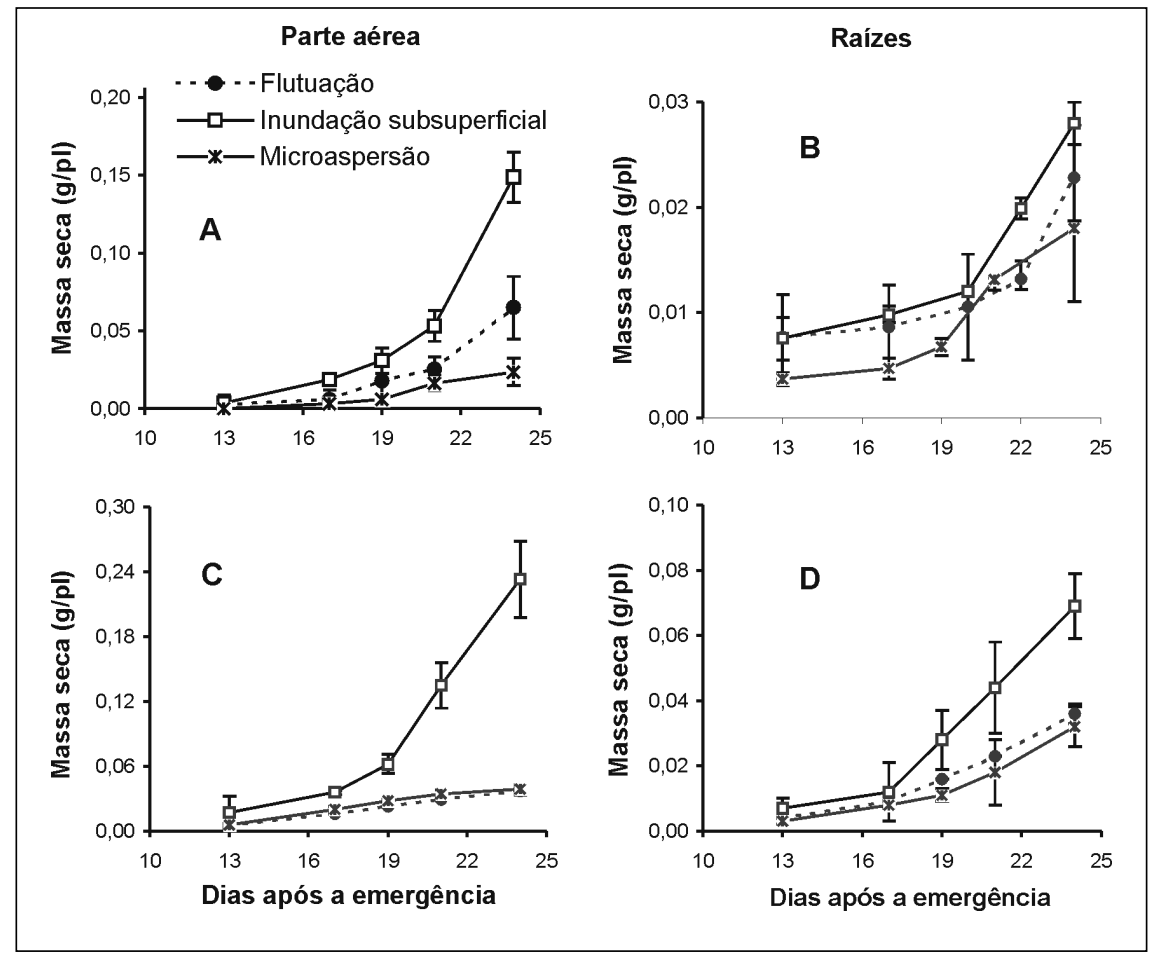

Figura 2. Médias de massa seca da parte aérea (A,C) e das raízes (B,D) no decorrer do crescimento de mudas de tomateiro produzidas empregando os métodos de irrigação por microaspersão, irrigação subsuperficial e flutuação, nos experimentos 1 (A,B) e 2 (C,D). Santa Maria, UFSM, 2000.

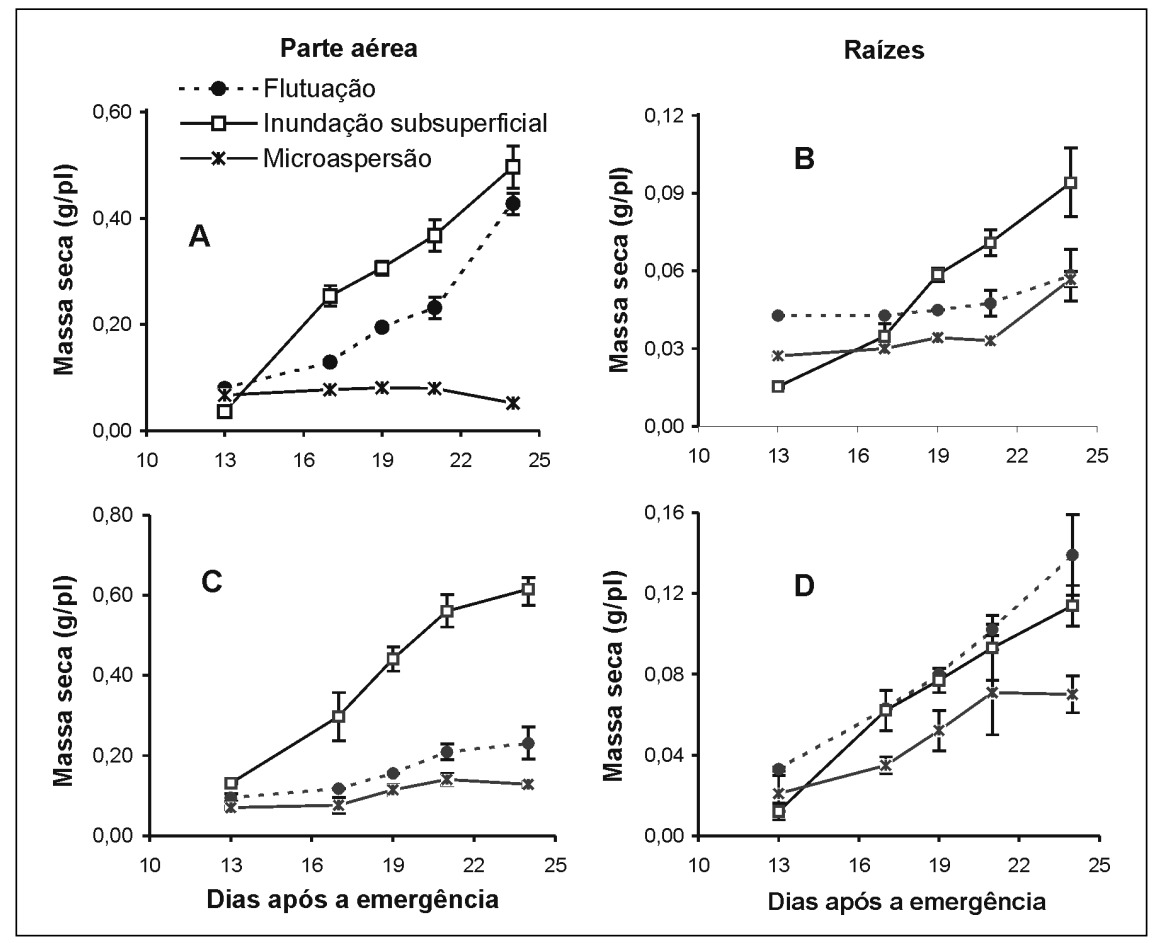

Figura 3. Médias de massa seca da parte aérea $(A, C)$ e das raízes $(B, D)$ no decorrer do crescimento de mudas de melão produzidas empregando os métodos de irrigação por microaspersão, irrigação subsuperficial e flutuação, nos experimentos 1 (A,B) e 2 (C,D). Santa Maria, UFSM, 2000. 